\title{
Faktor Yang Mempengaruhi Kepuasan Pelanggan Menginap di Chain Hotel
}

\author{
Dame Afrina Sihombing ${ }^{1)}$, Hellen ${ }^{2)}$ \\ Program Studi Pariwisata, Fakultas Ekonomi, Universitas Internasional Batam ${ }^{1,2)}$ \\ Jalan Gajah Mada, Baloi, Sei Ladi Batam, 29442 \\ E-Mail :dame@uib.ac.id
}

\begin{abstract}
Abstrak
Persaingan bisnis perhotelan saat ini semakin kompetitif yang sejalan dengan upaya pemerintah untuk meningkatkan sektor pariwisata. Indikator utama dalam industri perhotelan adalah kepuasan dari pelanggan. Penelitian ini dibuat dengan tujuan untuk mengetahui kepuasan dari setiap pelanggan yang telah menginap di chain hotel. Variabel yang digunakan dalam penelitian ini adalah keandalan, daya tanggap, jaminan, perhatian, bukti fisik terhadap kepuasan pelanggan. Populasi dalam penelitian ini adalah orang-orang yang pernah menggunakan fasilitas pelayanan di hotel. Sampel yang digunakan dalam penelitian ini adalah wisatawan nusantara yang sudah pernah menggunakan fasilitas pelayanan chain hotel. Penelitian ini menggunakan data primer yaitu dengan melakukan penyebaran kuesioner. Penelitian ini menggunakan SPSS versi 22 dengan kuesioner yang berhasil diuji sebanyak 301 dengan pengolahan data uji data deskriptif, uji validitas, uji reliabel dan uji t. Hasil dari penelitian menunjukkan bahwa keandalan, daya tanggap, jaminan, perhatian dan bukti fisik mempunyai pengaruh terhadap kepuasan pelanggan yang menginap di chain hotel.
\end{abstract}

Kata Kunci : Keandalan, Daya Tanggap, Jaminan, Perhatian, Kepuasan.

\section{Effect of Customer Satisfaction Staying at Chain Hotel}

\section{Abstract}

Competition in the hotel business is currently increasingly competitive in line with the government's efforts to improve the tourism sector. The main indicator of the hospitality industry is customer satisfaction. This research was made to know the satisfaction of each customer who has stayed at the hotel chain. The variables used in this study are reliability, responsiveness, assurance, attention, physical evidence of customer satisfaction. The population in this study are people who have used service facilities at the hotel. The sample used in this study were domestic tourists who had already used the chain hotel service facilities. This study uses primary data by distributing questionnaires. This study used SPSS version 22 with 301 questionnaires that were successfully tested with descriptive data processing, validity, reliability, and t-test. The results of the study indicate that reliability, responsiveness, assurance, attention, and physical evidence have an influence on customer satisfaction staying at the hotel chain.

Keyword: Reliability, Responsiveness, Assurance, Emphaty, Satisfaction.

\section{PENDAHULUAN}

Persaingan bisnis perhotelan saat ini semakin kompetitif yang sejalan dengan upaya pemerintah untuk meningkatkan sektor pariwisata. Di era leisure strategi bisnis hotel harus mengadopsi pengalaman dan menciptakan pengalaman yang "wow" serta kegembiraan kepada pengunjung. Para pelaku industri hotel harus mampu menggunakan teknologi untuk memberikan pelayanan prima kepada pelanggan untuk dapat beradaptasi dengan para pesaing baru (Tribun News, 2019).

Kualitas pelayanan saat ini sudah menjadi incaran industri-industri di Indonesia khususnya di bidang perhotelan. Hal ini dapat dilihat dari penyelenggaraan Service Quality Award 2018 yang diselenggarakan oleh lembaga Carre-CSSL dan bekerja sama dengan majalah Service Excellence yang memberikan penghargaan kepada perusahaan yang mampu memberikan pelayanan baik bagi para pelanggannya (Liputan 6, 2018). Hotel merupakan tempat penginapan bagi wisatawan yang melakukan perjalanan. Hotel tidak hanya menjual kamar, tetapi juga menjual jasa atau pelayanan. Maraknya perkembangan hotel menunjukkan bahwa persaingan di bidang perhotelan semakin ketat. Tingkat penghunian kamar hotel berbintang di Indonesia pada bulan November

http://ejournal.bsi.ac.id/ejurnal/index.php/khasanah 
2018 yang mengalami kenaikan dari $28,07 \%$ menjadi $32,93 \%$ dari bulan Juli ke Agustus 2020 (BPS, 2020) merupakan data untuk melihat persaingan yang terjadi dalam bidang perhotelan.

Dalam industri perhotelan, yang menjadi indikator utama adalah kepuasan dari para pelanggan melalui pelayanan yang baik dan ramah sehingga akan terjalin hubungan yang baik antara penyedia jasa dan penerima jasa. Disamping itu, pengusaha hotel harus berlomba dalam menarik minat pelanggan untuk menginap di hotel. Banyak cara dalam menarik minat pelanggan seperti melalui promosi, diskon dan juga memberikan pelayanan yang baik kepada pelanggan. Beberapa strategi yang bisa diambil dari promosi bisa dengan memberikan fasilitas yang lengkap, menawarkan keunikan, memberikan informasi terkait destinasi lokal di sekitaran hotel, bekerjasama dengan tour and travel setempat (Liputan 6, 2019).

Terdapat beberapa studi yang juga memberikan hasil beragam terhadap dampak dari kepuasan pelanggan, seperti (Boonitt \& Rompho, 2012) yang melakukan perbandingan pada hotel butik dan bisnis yang ada di Thailand, ekspektasi pelanggan terhadap kualitas pelayanan hotel butik lebih baik dari hotel bisnis. Kualitas layanan yang dimiliki masih rendah dan belum sesuai dengan yang diinginkan oleh pelanggan. (Karunaratne \& Jayawardena, 2010) dari hasil penilaian dari kepuasan pelanggan di Sri Lanka, ternyata variabel keandalan dan empati masih belum memenuhi kepuasan pelanggan. (Hossain, 2012) melakukan penelitian dari kepuasan pelanggan yang berkunjung ke Bazar Cox'z di Bangladesh dan mendapatkan hasil dari 5 variabel yang digunakan memiliki pengaruh signifikan terhadap kepuasan pelanggan. Variable empati merupakan variabel yang mendapatkan hasil terkuat yang kemudian daya tanggap, keandalan, jaminan dan bukti fisik. Di Indonesia sendiri penelitian yang meneliti terkait kepuasan pelanggan hotel belum banyak ditemukan pada chain hotel, masih meneliti terhadap hotel melati dan berbintang 3, 4 dan 5. Oleh karena itu, perlu dilakukan penelitian yang lebih intensif untuk melihat penilaian kepuasan pelanggan yang telah menginap di chain hotel dengan menggunakan pendekatan SERVQUAL yang telah di modifikasi seperti (Boonitt \& Rompho, 2012; Hossain, 2012; Karunaratne \& Jayawardena, 2010). Pengalaman dari para pelanggan diharapkan dapat memberikan masukan dan peningkatan terhadap pengembangan dari Chain Hotel.

\section{KAJIAN PUSTAKA}

\section{Kepuasan Pelanggan}

Kepuasan pelanggan telah menjadi aspek penting dalam bidang perhotelan. Hotel dapat bertahan dan berkembang dikarenakan retensi dan loyalitas seorang pelanggan. Melalui kepuasan pelanggan, sebuah hotel dapat mempertahankan pelanggannya. Kepuasan dan loyalitas pelanggan sangat bergantung kepada kualitas pelayanan yang mereka dapatkan di suatu hotel (Jana \& Chandra, 2016). Sebuah hotel harus melacak tingkat kepuasan pelanggan agar dapat mengetahui apa yang perlu ditingkatkan. Teknologi telah berkembang dari tahun ke tahun dan telah membantu bidang perhotelan dalam melacak statistik tentang kepuasan pelanggan. Survei online adalah cara populer dalam memantau kepuasan pelanggan sehingga manajemen dapat mengimplementasikan peningkatan berkelanjutan terhadap kualitas pelayanan dan fasilitas-fasilitas berdasarkan kebutuhan pelanggan yang dibutuhkan (Pearce \& Robinson, 2011).

\section{Keandalan}

Keandalan mengacu pada bagaimana perusahaan menepati janjinya baik dalam memberikan pelayanan berkualitas dan menepati janjinya dan dapat diandalkan (Rabean \& Haji-Othman, 2020). Kinerja dari sebuah layanan yang andal harus memenuhi setiap harapan pelanggan. Pelayanan yang diberikan harus diselesaikan dengan cara yang sama dan tanpa kesalahan (Rao, 2013).

\section{Daya Tanggap}

Daya tanggap adalah kemauan suatu perusahaan untuk membantu setiap pelanggannya dalam memberikan pelayanan yang cepat dan tepat (Rabean \& Haji-Othman, 2020). Daya tanggap adalah bagaimana cara memberikan pelayanan yang berkualitas dan tepat waktu sesuai kebutuhan dari pelanggan (Munusamy et al., 2010).

\section{Jaminan}

Jaminan dalam kualitas pelayanan lebih mengacu kepada karyawan suatu perusahaan. Karyawan yang baik adalah karyawan yang terampil dan dapat memperoleh kepercayaan dan keyakinan dari tamu (Munusamy et al., 2010). Perusahaan harus mampu memberikan jaminan keamanan kepada pelanggan (Rao, 2013). 


\section{Perhatian}

Perhatian bermaksud pada bagaimana suatu perusahaan menjaga dan memberikan perhatian khusus kepada tamunya sehingga membuat tamu merasa lebih special (Turgay Bucak, 2014). Jika tamu merasa dirinya dikhususkan dan diberikan perhatian yang baik oleh staf, maka dimungkinkan tamu tersebut akan kembali lagi (Sanjuq, 2014). Dari sudut pandang seorang pelanggan perhatian merupakan sebuah factor penting untuk menentukan tingkat keberhasilan dalam bisnis pariwisata dan perhotelan (Minh et al., 2015).

\section{Bukti Fisik}

Eksistensi dari sebuah perusahaan untuk menunjukkan kemampuannya seperti prestasi dari karyawan, fasilitas yang ditawarkan oleh perusahaan adalah merupakan bukti fisik secara nyata dari pelayanan yang diberikan (Ismail et al., 2017). Bukti fisik juga memperlihatkan kondisi dari staf serta penampilan, menunjukkan secara visual kondisi dari hotel dan juga staf (Minh et al., 2015).

\section{Model Penelitian dan Perumusan Hipotesis} Model pada penelitian ini adalah :

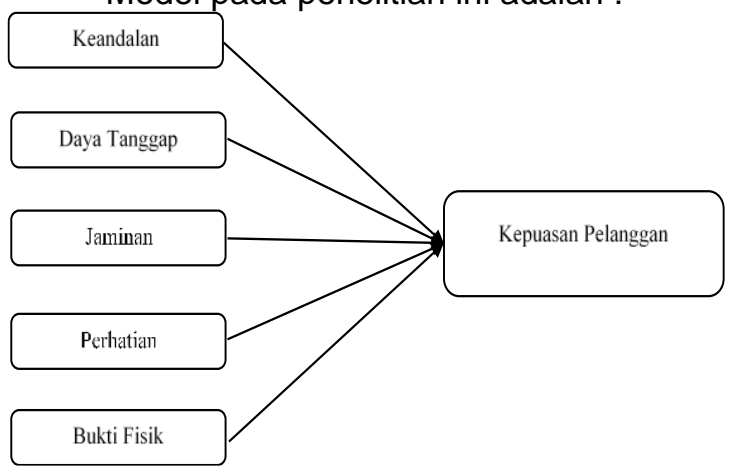

Sumber: Minh et al., 2015

Gambar 1 Model Penelitian

Berdasarkan model penelitian yang digambarkan diatas, maka dirumuskan hipotesis sebagai berikut:

$\mathrm{H} 1$ : Keandalan terhadap kepuasan memiliki pengaruh signifikan.

H2 : Daya tanggap terhadap kepuasan memiliki pengaruh signifikan.

H3 : Jaminan terhadap kepuasan memiliki pengaruh signifikan.

$\mathrm{H} 4$ : Perhatian terhadap kepuasan memiliki pengaruh signifikan.

H5 : Bukti fisik terhadap kepuasan memiliki pengaruh signifikan.

\section{METODE PENELITIAN}

\section{Jenis dan Desain Penelitian}

Pendekatan kuantitatif merupakan metode yang digunakan untuk penyusunan penelitian ini. Populasi di penelitian ini adalah orang-orang yang pernah menggunakan fasilitas pelayanan dari Chain Hotel. Populasi ini bersifat heterogen yang artinya bervariasi dalam usia, pendidikan terakhir, tujuan menginap di hotel maupun jenis kelamin. Objek atau subjek dengan kualitas yang telah peneliti tetapkan yang kemudian ditarik sebuah kesimpulan merupakan arti dari populasi (Sujarweni, 2018).

Sampel merupakan bagian dari karakteristik yang dimiliki oleh populasi yang berguna dalam penelitian (Sujarweni, 2018). Teknik sampeling di penelitian ini menggunakan non problabilitas sampeling. Untuk mendapatkan data yang lebih akurat, peneliti memilih sampel dengan pertimbangan atau kriteria-kriteria tertentu terlebih dahulu atau disebut dengan metode sampeling bertujuan atau purposive sampling. Unit sampel yang digunakan dalam penelitian ini adalah wisatawan nusantara yang pernah menerima pelayanan dari chain hotel.

(Sugiyono, 2017) memberikan saransaran tentang ukuran sampel untuk penelitian seperti Ukuran sampel yang layak dalam penelitian adalah antara 30-500. Berdasarkan teori tersebut, peneliti menyebarkan 488 kuesioner untuk menghindari adanya kuesioner cacat dan tidak kembali.

\section{Teknik Pengumpulan Data}

Penelitian ini menggunakan data yang diperoleh dan diolah langsung oleh peneliti dari subjek penelitian atau disebut dengan data primer. Data primer ini didapatkan dari hasil survei dengan melakukan penyebaran kuesioner yang diukur menggunakan skala Likert 5 poin. Penelitian ini menggunakan kuesioner model tertutup yang artinya responden hanya memilih jawaban yang disediakan oleh peneliti yang sesuai dengan pendapatnya sendiri (Sujarweni, 2018). Kuesioner disebarkan dalam bentuk Google Form kepada responden melalui media perantara whatsapp, line dan instagram dengan diberikan arahan dan penjelasan terlebih dahulu.

Pengumpulan data adalah melakukan analisis data yang didapatkan dari para responden. Metode analisis regresi berganda (multiple regression analysis) adalah metode yang digunakan peneliti dalam menganalisa data penelitian ini sedangkan untuk mengukur 
jawaban yang didapatkan, peneliti menggunakan skala nominal untuk analisa deskriptif yang dilakukan untuk menganalisa data berdasarkan uraian atau deskripsi dengan maksud tidak untuk menarik kesimpulan (Sugiyono, 2017), uji validitas untuk mengukur valid atau tidaknya suatu kuesioner (Sujarweni, 2018). Suatu kuesioner penelitian dinyatakan valid jika memiliki loading factor yang lebih besar dari 0,6 sedangkan jika loading factor lebih kecil dari 0,6 maka kuesioner penelitian tersebut dinyatakan tidak valid (Hair, Joseph $\mathrm{E}$ et al., 2014). Uji reliabilitas adalah apabila suatu kuesioner dikatakan reliabel atau handal jika jawaban seseorang terhadap pernyataan adalah konsisten atau stabil dari waktu ke waktu. Suatu kuesioner penelitian dinyatakan reliabel jika Cronbach's Alpha lebih besar dari 0,6 dan dinyatakan tidak reliabel jika Cronbach's Alpha lebih kecil dari 0,6 (Sujarweni, 2018). Uji $\mathrm{t}$ adalah untuk mengetahui hubungan variabel bebas terhadap variabel terikat secara parsial (Sujarweni, 2018). Kriteria dalam menentukan uji $t$ adalah dengan melihat tingkat probabilitas dimana jika tingkat probabilitas $<0,05$ maka Ho ditolak yang artinya terdapat pengaruh signifikan antara variabel bebas dengan variabel terikat dan jika tingkat probabilitas > 0,05 maka Ho diterima yang artinya tidak terdapat pengaruh signifikan antara variabel bebas dengan variabel terikat (Sujarweni, 2018). Total variabel yang diuji dalam penelitian ini adalah 5 (lima) variabel independen dan 1 (satu) variabel dependen.

\section{HASIL DAN PEMBAHASAN}

488 kuesioner yang disebarkan kepada wisatawan nusantara yang pernah menginap di Chain Hotel. Dari penyebaran tersebut terkumpul 302 kuesioner dan terdapat 1 kuesioner yang tidak lengkap karena responden tidak bersedia mengisi pertanyaan terkait tujuan menginap dan 2 pertanyaan pada variabel perhatian sehingga kuesioner tersebut tidak diikutkan dalam pengolahan data. Kuesioner yang telah diterima dan telah dipastikan lengkap kemudian diolah, karena penulis menunggu proses tersebut dan menjelasakan beberapa pertanyaan yang sulit dipahami, sehingga pengisian dapat berjalan dan bila tidak kembali penulis langsung mencoba menggantikan dengan responden lainnya.

Tabel 1. Kuesioner Diolah

\section{Keterangan}

Kuesioner Disebar

\begin{tabular}{lcc}
\hline $\begin{array}{l}\text { Kuesioner } \\
\text { Kembali }\end{array}$ & Tidak & 186 \\
\hline $\begin{array}{l}\text { Kuesioner } \\
\text { lengkap }\end{array}$ & Tidak & 1 \\
\hline \multicolumn{2}{l}{ Kuesioner Diolah } & 301 \\
\hline
\end{tabular}

Sumber : Data diolah

Analisa deskriptif dilakukan untuk menguji jenis kelamin, usia dan tujuan menginap. Didapatkan hasil bahwa responden berdasarkan jenis kelamin terdiri dari responden laki-laki berjumlah 150 orang $(49,83 \%)$, sedangkan responden perempuan berjumlah 151 orang $(50,17 \%)$.

Tabel 2. Jenis Kelamin

\begin{tabular}{lcc}
\hline Jenis Kelamin & Jumlah & Persentase \\
\hline Laki-laki & 150 & $49,83 \%$ \\
\hline Perempuan & 151 & $50,17 \%$ \\
\hline $\begin{array}{c}\text { Sumber : Data diolah } \\
\text { Usia responden dari }\end{array}$ & jumlah 301
\end{tabular}

responden terdapat 46 responden $(15,28 \%)$ berusia $<20$ tahun, 248 responden $(82,40 \%)$ berusia $20 \mathrm{~s} / \mathrm{d} 30$ tahun, 5 responden $(1,66 \%)$ berusia $31 \mathrm{~s} / \mathrm{d} 40$ tahun dan 2 responden $(0,66 \%)$ berusia $>40$ tahun. Kelompok usia yang mendominasi dalam penelitian ini adalah kelompok usia 20-30 tahun. Hal ini dikarenakan, usia 20-30 tahun di Indonesia adalah usia yang sudah sah memiliki Kartu Tanda Penduduk (KTP)/kartu identitas lainnya seperti Surat Izin Mengemudi (SIM)/Paspor sebagai salah satu syarat untuk melakukan check in di hotel karena data ini digunakan sebagai database tamu yang menginap di hotel, data ini juga diperlukan kepada imigrasi jika memang ada wisatawan mancanegara yang menginap di hotel tersebut (Travel Kompas, 2020).

\begin{tabular}{lcc}
\multicolumn{3}{c}{ Tabel 3. } \\
\multicolumn{1}{c}{ Bsia } & Jumlasarkan & Usia \\
\hline $\mathbf{0 - 3 0}$ thn & 294 & Persentase \\
\hline $\mathbf{3 1 - 4 0}$ thn & 5 & $97,68 \%$ \\
\hline >40 thn & 2 & $1,66 \%$ \\
\hline
\end{tabular}

Sumber : Data diolah

Responden dengan tujuan berwisata sebanyak 269 responden (89,37\%), berbisnis sebanyak 23 responden $(7,64 \%)$ dan tujuan lainnya sebanyak 9 responden (2,99\%). Dapat disimpulkan bahwa responden dengan tujuan berwisata mendominasi dalam penelitian ini. Alasannya dapat kita lihat dari survei Badan Pusat Statistik yang menunjukkan bahwa jumlah kunjungan wisatawan mancanegara ke Indonesia pada bulan Agustus 2018 mengalami kenaikan sebanyak $8,44 \%$ dibanding jumlah kunjungan pada Agustus 2017 yaitu dari 1,39 juta kunjungan menjadi 1,51 juta kunjungan. 
Tabel 4. Berdasarkan Tujuan Menginap Tujuan Menginap Jumlah Persenta se

\begin{tabular}{lcc} 
Berwisata & 269 & 89,37 \\
\hline Bisnis & 23 & 7,64 \\
\hline Lainnya & 9 & 2,99 \\
\hline
\end{tabular}

Sumber : Data diolah

Uji validitas dilakukan terhadap 28 (dua puluh delapan) item pertanyaan yang terdiri dari 4 (empat) item pertanyaan variabel keandalan, 3 (tiga) item pertanyaan variabel daya tanggap, 4 (empat) item pertanyaan variabel jaminan, 4 (empat) item pertanyaan variabel perhatian, 6 (enam) item pertanyaan variabel bukti fisik dan 7 (tujuh) pertanyaan kepuasan pelanggan. Dari hasil uji validitas terhadap 28 (dua puluh delapan) item pertanyaan terdapat 2 (dua) item pertanyaan yang tidak valid karena memiliki nilai muatan faktor dibawah 0,6 yang dimana staf front desk dirasa masih kurang berpenampilan menarik dan hotel belum menyediakan brosur atau petunjuk lain bagi pelanggan, sehingga yang tidak valid dieliminasi untuk penelitian selanjutnya (Hair, Joseph E et al., 2014). Tabel 5. Uji Validitas

\begin{tabular}{|c|c|c|}
\hline $\begin{array}{l}\text { Variabel } \\
\text { Pertanyaan }\end{array}$ & $\begin{array}{c}\text { Loading } \\
\text { Factor }\end{array}$ & Kesimpulan \\
\hline $\begin{array}{l}\text { Staf } \\
\text { memberikan } \\
\text { pelayanan } \\
\text { yang baik }\end{array}$ & 0,80 & Valid \\
\hline $\begin{array}{l}\text { Staf } \\
\text { memberikan } \\
\text { pelayanan } \\
\text { yang tepat } \\
\text { waktu }\end{array}$ & 0,80 & Valid \\
\hline $\begin{array}{l}\text { Staf } \\
\text { memecahkan } \\
\text { masalah } \\
\text { dengan baik }\end{array}$ & 0,78 & Valid \\
\hline $\begin{array}{l}\text { Staf } \\
\text { menyimpan } \\
\text { data tamu } \\
\text { secara rahasia }\end{array}$ & 0,65 & Valid \\
\hline $\begin{array}{l}\text { Staf selalu } \\
\text { bersedia untuk } \\
\text { menjawab } \\
\text { pertanyaan } \\
\text { saya }\end{array}$ & 0,78 & Valid \\
\hline $\begin{array}{l}\text { Staf selalu } \\
\text { tersedia untuk } \\
\text { merespon } \\
\text { permintaan } \\
\text { tamu }\end{array}$ & 0,81 & Valid \\
\hline $\begin{array}{l}\text { Staf fleksibel } \\
\text { sesuai dengan } \\
\text { permintaan } \\
\text { tamu }\end{array}$ & 0,80 & Valid \\
\hline
\end{tabular}

http://ejournal.bsi.ac.id/ejurnal/index.php/khasanah

\begin{tabular}{|c|c|c|}
\hline $\begin{array}{c}\text { Variabel } \\
\text { Pertanyaan }\end{array}$ & $\begin{array}{l}\text { Loading } \\
\text { Factor }\end{array}$ & Kesimpulan \\
\hline $\begin{array}{l}\text { Saya merasa } \\
\text { aman dan } \\
\text { nyaman } \\
\text { tinggal di hotel } \\
\text { tersebut }\end{array}$ & 0,81 & Valid \\
\hline $\begin{array}{l}\text { Staff memiliki } \\
\text { pengetahuan } \\
\text { tentang } \\
\text { informasi di } \\
\text { sekitar } \\
\text { (shopping, } \\
\text { museum dan } \\
\text { tempat wisata) }\end{array}$ & 0,74 & Valid \\
\hline $\begin{array}{l}\text { Staf } \\
\text { memenuhi } \\
\text { keterampilan } \\
\text { kerja }\end{array}$ & 0,76 & Valid \\
\hline $\begin{array}{l}\text { Hotel tersebut } \\
\text { memiliki staff } \\
\text { yang sopan }\end{array}$ & 0,79 & Valid \\
\hline $\begin{array}{l}\text { Staf } \\
\text { memberikan } \\
\text { perhatian } \\
\text { khusus } \\
\text { kepada tamu }\end{array}$ & 0,72 & Valid \\
\hline $\begin{array}{l}\text { Staf pahami } \\
\text { kebutuhan } \\
\text { khusus tamu }\end{array}$ & 0,77 & Valid \\
\hline $\begin{array}{l}\text { Sikap yang } \\
\text { baik saat } \\
\text { menerima } \\
\text { feedback dari } \\
\text { tamu }\end{array}$ & 0,80 & Valid \\
\hline $\begin{array}{l}\text { Hotel tersebut } \\
\text { menghadiri } \\
\text { menu } \\
\text { makanan yang } \\
\text { sehat }\end{array}$ & 0,66 & Valid \\
\hline $\begin{array}{l}\text { Hotel tersebut } \\
\text { memiliki lokasi } \\
\text { yang strategis }\end{array}$ & 0,70 & Valid \\
\hline $\begin{array}{l}\text { Hotel tersebut } \\
\text { memiliki } \\
\text { fasilitas dan } \\
\text { perlengkapan } \\
\text { yang lengkap }\end{array}$ & 0,72 & Valid \\
\hline $\begin{array}{l}\text { Hotel tersebut } \\
\text { memiliki kamar } \\
\text { yang menarik }\end{array}$ & 0,73 & Valid \\
\hline $\begin{array}{l}\text { Front desk } \\
\text { agent yang } \\
\text { berpenampilan } \\
\text { menarik }\end{array}$ & 0,58 & Tidak Valid \\
\hline $\begin{array}{l}\text { Hotel tersebut } \\
\text { menyediakan } \\
\text { brosur dan } \\
\text { petunjuk jalan }\end{array}$ & 0,52 & Tidak Valid \\
\hline
\end{tabular}




\begin{tabular}{|c|c|c|}
\hline $\begin{array}{c}\text { Variabel } \\
\text { Pertanyaan }\end{array}$ & $\begin{array}{c}\text { Loading } \\
\text { Factor }\end{array}$ & Kesimpulan \\
\hline $\begin{array}{l}\text { Hotel tersebut } \\
\text { merupakan } \\
\text { tempat yang } \\
\text { baik untuk } \\
\text { beristirahat }\end{array}$ & 0,75 & Valid \\
\hline $\begin{array}{l}\text { Saya akan } \\
\text { tetap tinggal di } \\
\text { hotel ini }\end{array}$ & 0,70 & Valid \\
\hline $\begin{array}{l}\text { Saya akan } \\
\text { merekomenda } \\
\text { sikan hotel ini } \\
\text { kepada orang } \\
\text { lain }\end{array}$ & 0,65 & Valid \\
\hline $\begin{array}{l}\text { Saya akan } \\
\text { menginap di } \\
\text { hotel ini lain } \\
\text { kali }\end{array}$ & 0,78 & Valid \\
\hline $\begin{array}{lr}\text { Saya akan } \\
\text { membeli jasa } \\
\text { hotel ini }\end{array}$ & 0,81 & Valid \\
\hline $\begin{array}{l}\text { Saya akan } \\
\text { manganjurkan } \\
\text { teman dan }\end{array}$ & 0,80 & Valid \\
\hline $\begin{array}{l}\text { saudara saya } \\
\text { untuk } \\
\text { mengunjungi } \\
\text { hotel ini }\end{array}$ & & \\
\hline $\begin{array}{l}\text { Saya merasa } \\
\text { kinerja hotel ini } \\
\text { sangat kuat }\end{array}$ & 0,75 & Valid \\
\hline $\begin{array}{l}\text { Saya akan } \\
\text { mempertimban } \\
\text { gkan hotel ini } \\
\text { sebagai pilihan }\end{array}$ & 0,80 & Valid \\
\hline utama saya & & \\
\hline ketika & & \\
\hline $\begin{array}{l}\text { butuh jasa } \\
\text { penginapan }\end{array}$ & & \\
\hline
\end{tabular}

Sumber : Data diolah

Hasil uji reliabilitas data menunjukkan bahwa semua variabel memiliki nilai cronbach's alpha yang lebih besar dari 0,60 (Sujarweni, 2018), yang berarti tidak ada pertanyaan yang tidak reliabel dari masingmasing variabel, sehingga seluruh variabel dinyatakan konsisten.

Tabel 6. Uji Reliabilitas

\begin{tabular}{lcc}
\hline Variabel & $\begin{array}{c}\text { Cronbach's } \\
\text { Alpha }\end{array}$ & Kesimpulan \\
\hline Keandalan & 0,86 & Reliabel \\
Daya & 0,88 & Reliabel \\
Tanggap & & Reliabel \\
Jaminan & 0,87 & Reliabel \\
Perhatian & 0,87 & Reliabel \\
Bukti Fisik & 0,84 & Reliabel \\
Kepuasan & 0,89 & \\
Pelanggan & & \\
\hline \hline
\end{tabular}

Sumber : Data diolah

Hasil uji $t$ telah dilakukan dan mendapatkan hasil bahwa keandalan, daya tanggap, jaminan, perhatian, bukti fisik, berpengaruh signifikan terhadap kepuasan pelanggan. Hal ini dikarenakan responden akan melakukan dan menyebarkan informasi kepada orang lain dan akan mempertimbangkan hotel ini sebagai tujuan utama jika membutuhkan penginapan.

Tabel 7. Uji T

\begin{tabular}{lccc}
\hline Variabel & $\begin{array}{c}\text { Unstandarized } \\
\text { Coefficients }\end{array}$ & $\mathbf{t}$ & Sig. \\
\hline Keandalan & 0,38 & 9,61 & 0,00 \\
Daya & 0,73 & 14,63 & 0,00 \\
Tanggap & & & \\
Jaminan & 0,31 & 7,23 & 0,00 \\
Perhatian & 0,07 & 2,11 & 0,04 \\
Bukti Fisik & 0,33 & 7,74 & 0,00 \\
\hline Sumber
\end{tabular}

Sumber : Data diolah

\section{PENUTUP}

Penelitian ini bertujuan untuk mengetahui apakah terdapat pengaruh antara variabel keandalan, daya tanggap, jaminan, perhatian dan bukti fisik terhadap kepuasan pelanggan dengan mengadopsi Servqual. Penelitian ini mendapatkan hasil bahwa dari lima variabel yang diteliti, semuanya menunjukkan hubungan signifikan terhadap kepuasan pelanggan yang didapatkan dari hasil pengolahan data yang telah dilakukan dengan menggunakan SPSS versi 22 pada Uji $\mathrm{T}$.

Para pengusaha harus memperhatikan setiap aspek, selain pentingnya iklan dan promosi, kualitas keandalan staf berperan penting sebagai pendorong untuk menaikkan tingkat kepuasan pelanggan di perusahaan jasa. Daya tanggap menggambarkan dampak terkuat pada kepuasan pelanggan dengan koefisien beta tertinggi. Dimana staf selalu menjawab pertanyaan dari pelanggan dan selalu bersedia merespon permintaan yang diberikan oleh setiap pelanggan.

Kemudian diikuti dengan keandalan dimana staf harus meningkatkan pelayanan kepada pelanggan, menyimpan data pelanggan dan tidak menyebarluaskan serta membantu keluhan dari setiap pelanggan harus menjadi topik penting untuk ditingkatkan.

Bukti fisik terkait dengan lokasi dari hotel tersebut. Hotel juga harus menyediakan fasilitas dan informasi yang dapat membantu para pelanggan. Jaminan adalah dimana pihak hotel dapat memberikan kepastian keamanan bagi setiap pelanggan dan memiliki pengetahuan seputar daerah atau area 
disekitar hotel seperti taman hiburan, museum dan destinasi.

Perhatian adalah bagaimana cara dari setiap staf memberikan perhatian khusus sesuai dengan permintaan dari pelanggan dan memahami kebutuhan atau permintaan khusus dari para pelanggan. Staf juga memberikan ekspresi dan sikap yang positif saat menerima masukan dari para pelanggan. Dari hal-hal tersebut menunjukkan bahwa kualitas pelayanan berperan penting sebagai pendorong dalam meningkatkan kepuasan pelanggan yang mengarah pada loyalitas pelanggan serta keuntungan bagi hotel.

\section{Rekomendasi}

Berdasarkan hasil penelitian, untuk selanjutnya diharapkan: (1) Penelitian ini masih dilakukan terhadap pelangggan di Kota Batam saja, perlu dilakukan penelitian yang lebih intensif lagi di Indonesia dan bahkan Asia. (2) peneliti selanjutnya dapat menambahkan variabel-variabel lainnya seperti harga dan citra perusahaan. (3) bagi para pengusaha khususnya dalam bidang perhotelan diharapkan dapat selalu meningkatkan kemampuan staf untuk memberikan jaminan, keandalan dalam melakukan pelayanan kepada pelanggan baik diberikan melalui pelatihan kemampuan ataupun pemahaman prosedur yang lebih mendalam.

\section{DAFTAR PUSTAKA}

Boonitt, S., \& Rompho, N. (2012). Measuring Service Quality Dimensions: An Empirical Analysis of Thai Hotel Industry. International Journal of Business Administration, 3(5), 52-63. https://doi.org/http://dx.doi.org/10.5430/ijb a. v3n5p52

BPS. (2020). Tingkat Hunian Kamar Hotel 2019.

https://www.bps.go.id/indicator/16/122/1/t ingkat-penghunian-kamar-pada-hotelbintang.html

Hair, Joseph E, J., Black, C, W., Jabin, J, B., \& Anderson, E, R. (2014). A Primer on Partial Least Squares Structural Equation Modeeling $\quad$ (PLS-SEM). SAGE Publications, Inc.

Hossain, M. J. (2012). Impact of service quality on customer satisfaction: A case of tourism industry in Bangladesh. International Journal of Research in Finance \& Marketing, 2(2), 1-25.

Ismail, A., Rose, I. R., Tudin, R., \& Dawi, N. M.
(2017). Relationship between Service Quality and Behavioral Intentions: The Mediating Effect of Customer Satisfaction. Etikonomi, 16(2), 125-144. https://doi.org/10.15408/etk.v16i2.5537

Jana, A., \& Chandra, B. (2016). Mediating Role of Customer Satisfaction in the MidMarket Hotels: An Empirical Analysis. Indian Journal of Science and Technology, $9(1), \quad 1-16$. https://doi.org/10.17485/ijst/2016/v9i1/81 973

Karunaratne, W. M. K. K., \& Jayawardena, L. N. A. C. (2010). Assessment of Customer Satisfaction in a Five Star Hotel-A Case Study. Tropical Agricultural Research, 21(3), 258-265.

Liputan 6. (2018). 267 Merek Indonesia Raih Penghargaan di Service Quality Award 2018.

Liputan 6. (2019). 5 Tips Mempromosikan Hotel dan Properti Agar Makin Dikenal.

Minh, N. H., Thu Ha, N., Chi Anh, P., \& Matsui, Y. (2015). Service quality and customer satisfaction: A case study of hotel industry in Vietnam. Asian Social Science, 11(10), 73-85. https://doi.org/10.5539/ass.v11n10p73

Munusamy, J., Chelliah, S., \& Mun, H. (2010). Service quality delivery and its impact on customer satisfaction in the banking sector in Malaysia. International Journal of Innovation, ..., 1(4), 398-404. http://www.ijimt.org/papers/71-M461.pdf

Pearce, J., \& Robinson, R. (2011). Strategic Management: Formulation, Implementation \& Control (12th Revis). Mcgraw Hill Higher Education;

Rabean, Q. binti, \& Haji-Othman, Y. (2020). Customer Satisfaction in Hotel Cinta Sayang Resort, Sungai Petani, Kedah, Malaysia: a Qualitative Approach. Prosiding Seminar, 3(1), 97. https://doi.org/10.32503/prosidingseminar .v0i0.12

Rao, P. S. (2013). Impact of Service Quality on Customer Satisfaction in Hotel Industry. IOSR Journal Of Humanities And Social Science, 18(5), 39-44. https://doi.org/10.9790/0837-1853944

Sanjuq, G. (2014). The Impact of Service Quality Delivery on Customer Satisfaction in the Banking Sector in Riyadh, Saudi Arabia. International Journal of Business Administration, 5(4), 77-84. https://doi.org/10.5430/ijba.v5n4p77

Sugiyono. (2017). Metode Penelitian Kualitatif: Untuk penelitian yang bersifat: eksploratif, enterpretif, interaktif, dan 
konstruktif. Alfabeta.

Sujarweni, V. W. (2018). Metodologi Penelitian Bisnis dan Ekonomi Pendekatan Kuantitatif. Pustaka Baru Press.

Travel Kompas. (2020). No Title.

Tribun News. (2019). Persaingan Bisnis Hotel Makin Sengit, Pemain Harus Cepat Beradaptasi.

https://www.tribunnews.com/bisnis/2019/ 08/21/persaingan-bisnis-hotel-makinsengit-pemain-harus-cepat-beradaptasi Turgay Bucak, P. (2014). The Effect of Service Quality on Customer Satisfaction: A Research on Hotel Businesses. International Journal of Education and Research Gržinić, 2(1), 1-12. http://www.ijern.com/journal/January2014/38.pdf 